\title{
Third occipital nerve headache: a prevalence study
}

\author{
Susan M Lord, Les Barnsley, Barbara J Wallis, Nikolai Bogduk
}

\begin{abstract}
A consecutive series of 100 patients was studied to determine the prevalence of third occipital nerve headache in patients with chronic neck pain ( $>$ three months in duration) after whiplash. Seventy one patients complained of headache associated with their neck pain. Headache was the dominant complaint of 40 patients, but was only a secondary problem for the other 31. Each patient with headache underwent double blind, controlled diagnostic blocks of the third occipital nerve. On two separate occasions the nerve was blocked with either lignocaine or bupivacaine, in random order. The diagnosis of third occipital nerve headache was made only if both blocks completely relieved the patient's upper neck pain and headache and the relief lasted longer with bupivacaine. The prevalence of third occipital nerve headache among all 100 whiplash patients was $27 \%(95 \%$ confidence interval (95\% CI) 18-36\%) and among those with dominant headache the prevalence was as high as $53 \%(95 \%$ CI $37-68 \%)$. There were no distinguishing features on history or examination that enabled a definitive diagnosis to be made before the nerve blocks. Those patients with a positive diagnosis, however, were significantly more likely to be tender over the C2-3 zygapophysial joint $(p=0.01)$. Third occipital nerve headache is a common condition in patients with chronic neck pain and headache after whiplash. Third occipital nerve blocks are essential to make this diagnosis.
\end{abstract}

(F Neurol Neurosurg Psychiatry 1994;57:1187-1190)

The notion of third occipital nerve headache was introduced by Bogduk, et al. ${ }^{1}$ They reported seven, ${ }^{1}$ and subsequently 11 patients $^{2}$ with chronic headache whose pain was relieved by selective blockade of the third occipital nerve with small amounts of local anaesthetic. On the basis of anatomical and circumstantial clinical evidence, they argued that the pain stemmed from the C2-3 zygapophysial joint, which is innervated by the third occipital nerve. The pain was believed to be due to post-traumatic arthropathy, and the headache constituted referred pain to the head from the cervical spine.

This entity attracted some degree of recognition, ${ }^{3}$ but also detractors. Critics maintained that the blocks used were not specific, and that inter alia relief of pain from muscle spasm had not been excluded. ${ }^{4}$ Since that time, studies have been concluded which show that third occipital nerve blocks do not anaesthetise structures that might reasonably be a source of pain other than the C2-3 zygapophysial joint. ${ }^{6}$ The local anaesthetic remains concentrated around the target nerve and joint. It does not spread to reach the spinal nerve or ventral ramus, and it does not infiltrate surrounding muscles.

The technique used to diagnose third occipital nerve headache is therefore target specific and valid. What might be raised, however, is the criticism that the initial reports of this condition were based on poorly controlled, unblinded studies. The possibility of false positive responses ${ }^{7}$ was not excluded. Furthermore, the prevalence, and hence the clinical significance of third occipital nerve headache, could not be gauged from studies of only a dozen or so patients.

The present study considered both these issues. The prevalence of third occipital nerve headache was determined in a consecutive series of patients with pain ascribed to whiplash injury. The diagnosis was established with double blind, controlled, diagnostic blocks of the third occipital nerve. To identify true positive responders, each patient was subjected to two blocks, with different local anaesthetics on separate occasions. The validity of such double blocks has been established in a preceding study. ${ }^{8}$

\section{Methods}

The patients selected for study were the first 100 consecutive patients entering a research programme considering the cause and treatment of neck pain after whiplash injury. The criteria for entry were that patients must have neck pain of more than three months in duration after, and attributed to, a motor vehicle accident. All patients must have consulted a specialist before referral and only referrals from medical practitioners were accepted.

Patients were drawn largely from within the city of Newcastle and its surrounding rural regions, but also from Sydney and other parts of the state of New South Wales. The first 100 patients were aged 41 (11) years (mean (SD)) with a male:female ratio of $1: 2$. After a medical history and examination had been obtained, a psychological questionnaire (SCL-90-R) ${ }^{9}$ was given to all patients by a psychologist. 
Of these 100 patients, 29 did not experience headache. The remaining 71 patients constituted the study sample. Of these, there were 40 patients for whom headache was the predominant complaint in that it overshadowed any neck pain. For the other 31 patients, headache was only incidental or of a lesser severity than their neck pain.

All 71 patients with headache systematically underwent double blind, controlled blocks of the third occipital nerve. The use of an inactive control agent, such as normal saline, was not feasible because the third occipital nerve consistently has a cutaneous representation. ${ }^{1}$ Hence, the presence or absence of cutaneous anaesthesia after each block would provide a cue to both patient and observer, thereby confounding the blinding process. Accordingly, an active control agent-a local anaesthetic with a different duration of action-was used in preference to saline.

Under repeated fluoroscopic screening a $25 \mathrm{~g}, 90 \mathrm{~mm}$ spinal needle was inserted by a lateral approach to the third occipital nerve. Three target points were selected to ensure that the variable course of the nerve across the C2-3 joint was adequately bracketed (figure). ${ }^{10}$ Each procedure was performed in the presence of a medically qualified, independent observer who corroborated the radiographic position of the operator's needle before any injection. At each target point $0.5 \mathrm{ml}$ of local anaesthetic was injected slowly, at a rate of $1.2 \mathrm{ml}$ per minute.

Technical adequacy of the blocks was determined by examining the patient for numbness in the cutaneous territory of the third occipital nerve. If appropriate cutaneous
Lateral radiograph showing a needle in position for a third occipital nerve block. The course of the third occipital nerve is shown as a dotted line. Articular branches supplying the C2-3 zygapophysial joint arise from the underside of this nerve as it crosses the lateral and dorsal aspects of the joint.

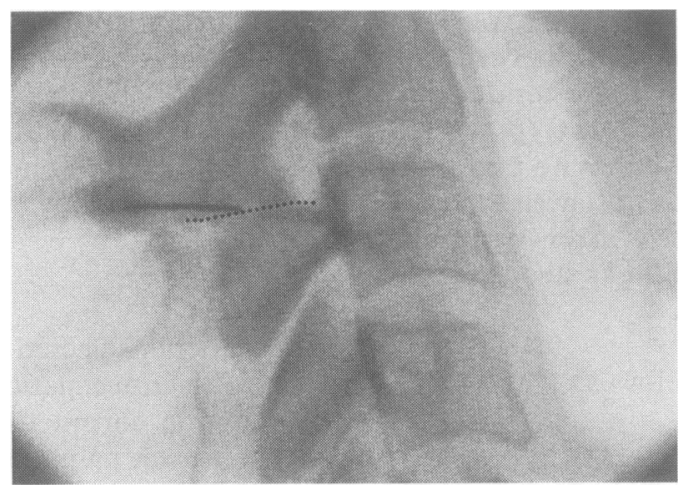

Table 1 Results of investigation for third occipital nerve headache in 100 consecutive patients with chronic neck pain after whiplash

\begin{tabular}{lclc}
\hline & $\begin{array}{l}\text { Headache worse } \\
\text { than neck pain } \\
n=40\end{array}$ & $\begin{array}{l}\text { Headache less } \\
\text { than neck pain } \\
n=31\end{array}$ & $\begin{array}{l}\text { Neck pain } \\
\text { only } \\
n=29\end{array}$ \\
\hline Withdrawals & 3 & 4 & 5 \\
Investigations not completed & 3 & 6 & \\
Third occipital nerve headache & 21 & 6 & \\
Not third occipital nerve headache & 3 & 0 & \\
$\quad$ False positive response & 6 & 1 & \\
All zygapophysial joints negative & 1 & 3 & \\
Still under investigation & 3 & 1 & \\
Other zygapophysial joints positive & 0 & 2 & \\
C3-4 & 0 & 7 & \\
C4-5 & 0 & 1 & \\
C5-6 & 0 & & \\
\hline
\end{tabular}

numbness ensued the block was considered technically adequate. If no numbness ensued the block was considered inadequate, and the patient was rescheduled for another attempt.

Each patient was randomly allocated to receive either a short acting agent, $2 \%$ lignocaine, or a long acting agent, $0.5 \%$ bupivacaine, for the first block. Patients who obtained no relief of their headache after a technically adequate first block were considered not to have third occipital nerve headache and underwent no further investigations at the C2-3 level. Patients who obtained relief of their headache after their first block, returned after an interval of at least two weeks for a control block with the agent that they did not receive on the occasion of their first block.

The patient's responses to these blocks were assessed by the independent observer, by a telephone interview on the evening or day after the block. Neither the patient nor the independent observer knew which agent was used on each occasion. The patient was asked to report the quality and duration of any pain relief experienced.

A positive diagnosis was made only if the patient's pain was completely and reproducibly relieved by the blocks and provided that the patient was able to correctly discriminate the relative durations of the two local anaesthetics. All other responses were considered negative. A statistical analysis was performed to determine the likelihood that all of those who satisfied these criteria were merely guessing. A binomial was calculated with $n$ being the number of patients who reported reproducible relief, and $p$ equal to 0.5 (the probability of guessing the longer acting agent).

Patients who failed to obtain relief of their neck pain and headache after third occipital nerve blocks subsequently underwent diagnostic blocks of their lower cervical zygapophysial joints in an effort to determine the source of their pain. The techniques used and the patients' responses to these blocks are the subject of other reports. ${ }^{811}$

\section{Results}

Twelve patients withdrew from the study before undergoing diagnostic blocks, five from the group with no headache, three from the group with headache as their predominant complaint, and four from the group with headache but predominant neck pain (table).

From the reasons for withdrawal that were volunteered by the patients who withdrew, there was no consistent factor responsible for their decision. There was a higher proportion of females among the withdrawals (male:female ratio of 1:6) but otherwise as a group, these patients closely resembled the remaining study group with respect to age, employment state, mode of accident, and duration and severity of pain. Psychological assessment showed no significant differences between the patients who withdrew and remained with respect to interpersonal problems, obsessive compulsive behaviour, 
depression, anxiety, phobic anxiety, paranoia, or psychoticism. The only significant difference between the two groups was that the patients who withdrew reported fewer somatic symptoms (Mann-Whitney U test, $\mathrm{p}<0.05$ ).

Of the 64 patients with headache remaining in the study, nine did not complete the investigation (table). For logistic reasons, three patients with headache as their predominant complaint completed only one technically satisfactory third occipital nerve block, to which they had a positive response. One patient had moved to another state; another was recovering from a second motor vehicle accident that occurred before receiving the control block; and the third patient experienced an idiosyncratic reaction to local anaesthetic that precluded the administration of further blocks.

Six patients for whom headache was not their major complaint did not complete investigation. One of these patients had a positive response to their initial third occipital nerve block but moved to another state before completing the control block; one experienced travelling difficulties that prevented further attendance; and another had no recurrence of pain after the initial block. A further three patients offered false positive responses when blocks of their lower cervical zygapophysial joints were undertaken to relieve their neck pain. In view of these responses, third occipital nerve blocks were not undertaken in these patients.

Of the 55 patients who completed investigation, 27 unequivocally satisfied the predetermined criteria for third occipital nerve headache. These patients obtained pain relief after both blocks, and reported a longer duration of relief after bupivacaine. The median duration of relief after lignocaine was 120 minutes (interquartile range: 55-270 minutes), and after bupivacaine was 490 minutes (interquartile range: 225-1410 minutes).

A further three patients reported relief after both blocks but did not discriminate the longer acting agent. The binomial calculation shows that it is extremely improbable that 27 out of 30 patients merely guessed the correct order of the anaesthetics $(\mathrm{p}<0.0001)$.

The other 25 patients who completed investigation had the C2-3 zygapophysial joint excluded as the source of their headache. Fourteen patients obtained complete relief of their neck pain and headache after blocks of cervical zygapophysial joints at levels below C2-3. Three of these patients were from the group with headache as their predominant complaint; 11 had neck pain as their predominant complaint. The table shows the segments at which these patients were symptomatic.

Seven patients had all relevant cervical zygapophysial joints investigated and excluded as the source of their pain. Four patients who did not respond to third occipital nerve blocks are still undergoing investigations of their lower cervical zygapophysial joints.

In the present sample, the overall prevalence of headache was $71 \% \quad(95 \% \quad$ CI
$62-80 \%)$. Among those patients with headache as their predominant complaint the prevalence of third occipital nerve headache, in a "worst case" analysis, was 21 of 40 or $53 \%$ (95\% CI 37-68\%). For those patients in whom headache was only a secondary complaint, the prevalence of third occipital nerve headache was only six of 31 or $19 \%$ (95\% CI 5-33\%). A third of these patients, however, had their headaches relieved by blocks of lower cervical zygapophysial joints (table).

There were no notable differences between those patients who responded to third occipital nerve blocks and those who did not, with respect to demographic features, psychological profiles, mode of accident, and the duration, frequency, severity, and quality of their pain. Certain clinical features, however, distinguished those patients with third occipital nerve headache.

Third occipital nerve headache is significantly more common in patients in whom headache, rather than neck pain, is the predominant complaint. Furthermore, tenderness over the C2-3 zygapophysial joint is a hallmark of these patients. As a diagnostic test for third occipital nerve headache, this tenderness has a sensitivity of $85 \%$, a positive likelihood ratio of $1 \cdot 7$, and a negative likelihood ratio of 0.3 . That is, if tenderness is present over the C2-3 level, the post-test odds for having third occipital nerve headache are 1.7 times the pretest odds, and conversely, if tenderness is absent, the post-test odds are 0.3 times the pretest odds. The combination of headache as the predominant complaint plus tenderness over $\mathrm{C} 2-3$ carries a positive likelihood ratio of $2 \cdot 1$, a higher likelihood ratio than for either feature alone.

\section{Discussion}

The present study was referral based. It deliberately sought to recruit and study patients representative of those who seek specialist attention for their chronic neck pain after whiplash. Demographically, and with respect to clinical features, the present sample did not differ from those described in other studies of whiplash. ${ }^{12-17}$

The present study considered and resolved the persisting issues concerning third occipital nerve headache. It is clearly not a rare disorder. On the basis of double blind, controlled blocks, the prevalence of third occipital nerve headache in patients with chronic neck pain after whiplash is $27 \%$. Among patients with headache after whiplash the prevalence of third occipital nerve headache is $38 \%$, and among patients in whom headache is their predominant complaint the prevalence rises to $53 \%$. No other basis for headache after whiplash has been shown to be as common, and no other form of headache has been subjected to as rigorous, scientific scrutiny.

Previous studies of third occipital nerve headache were not able to offer diagnostic clinical features of this condition, ${ }^{1}$ but the present study has rectified this deficiency. Headache as the predominant complaint and 
tenderness over the C2-3 zygapophysial joint on the side of pain are characteristic of the condition. Tenderness is the most sensitive sign and the combination of the two features carries a positive likelihood ratio of $2 \cdot 1$. Patients who lack these features are unlikely to have third occipital nerve headache. Nevertheless, controlled diagnostic blocks remain the definitive means of establishing the diagnosis.

The pathology and pathophysiology of third occipital nerve headache have not yet been determined. It could be that third occipital nerve blocks are as non-specific as blocks of the greater occipital nerve or $\mathrm{C} 2$ ganglion, ${ }^{18}$ and operate simply by reducing afferent input to the trigeminocervical nucleus. Circumstantial evidence, however, favours an arthropathic model.

The biomechanics of whiplash renders the cervical zygapophysial joints liable to injury, and experiments in animals ${ }^{19}$ and on cadavers, ${ }^{2021}$ as well as postmortem studies ${ }^{22}$ have shown fractures and capsular and intracapsular injuries of these joints that are not evident radiologically. Occasionally, some such injuries may be evident on special imaging studies ${ }^{202324}$ but there is no evidence that even high resolution CT or MRI can identify all such injuries.

Evidence that the patients in the present study had joint pain stems from the finding that those who entered a double blind, controlled trial of intra-articular local anaesthetic and intra-articular steroids, all obtained relief of their pain, albeit for various periods. The details of these responses are considered elsewhere. ${ }^{25}$

Notwithstanding the lack of data on pathology, the results of the present clinical study should be compelling. Third occipital nerve headache is not the only basis for headache associated with neck pain after whiplash. Indeed, the present study itself found that many patients have pain and headache arising from levels below $\mathrm{C} 2-3$; others have reported pain stemming from the lateral atlantoaxial joints ${ }^{26} 27$ and pain mediated by the $\mathrm{C} 2$ spinal nerve. ${ }^{18}$ Third occipital nerve headache is none the less so common in patients with post-traumatic neck pain that it can no longer be ignored or overlooked as an entity.

At present, there is no validated treatment for third occipital nerve headache. In the past, intra-articular injections of steroids were advocated for the treatment of pain from the C2-3 zygapophysial joint, but only on the basis of uncontrolled studies. A recent randomised, double blind, controlled trial of this treatment, however, failed to vindicate its effectiveness. ${ }^{25}$ Another method of treatment is percutaneous radiofrequency neurotomy of the third occipital nerve. Although pilot studies of this technique have been encouraging, it cannot be endorsed until it has been formally evaluated under double blind, controlled conditions. We are in the process of conducting such a study, and results should be available in 1995.

This study was supported by a grant from the Motor Accidents Authority of New South Wales. All procedures were performed at the Newcastle Mater Misericordiae Hospital, Waratah, New South Wales, Australia.

1 Bogduk N, Marsland A. On the concept of third occipital headache. $f$ Neurol Neurosurg Psychiatry 1986;49: 775-80.

2 Jull G. Manual diagnosis of C2-3 headache. Cephalalgia 1993;5 (suppl 3):308-9.

3 Editorial. Third-nerve headache. Lancet 1986;ii:374.

4 Edmeads J. The cervical spine and headache. Neurology 1988;38:1874-8.

5 Balla JI, Iansek R. Headaches arising from disorders of the cervical spine. In: Hopkins A, ed. Headache problems in diagnosis and management. London: $\mathrm{W}$ B Saunders, 1988:241-67.

6 Barnsley L, Bogduk N. Medial branch blocks are specific for the diagnosis of cervical zygapophysial joint pain. Reg Anesth 1993;18:343-50.

7 Barnsley L, Lord SM, Wallis BJ, Bogduk N. False-positive rates of cervical zygapophysial joint blocks. Clin $\mathcal{F}$ Pain 1993;9:124-30.

8 Barnsley L, Lord SM, Bogduk N. Comparative local anaesthetic blocks in the diagnosis of cervical

9 Derogatis LR. SCL-90-R: Administration, scoring and procedures manual-II. Towson: Clinical Psychometric Research, 1983.

10 Bogduk N. The clinical anatomy of the cervical dorsal rami. Spine 1982;7:319-30.

11 Barnsley L, Lord SM, Wallis BJ, Bogduk N. Chronic cervical zygapophysial joint pain after whiplash: a prospective prevalence study. Spine 1994 (in press).

12 Balla JI. The late whiplash syndrome. Aust $N Z \mathcal{f}$ Surg 1980;50:610-4.

13 Gargan MF, Bannister GC. Long-term prognosis of softtissue injuries of the neck. F Bone foint Surg Br 1990; 72:901-3.

14 Maimaris C, Barnes MR, Allen MJ. "Whiplash injuries" of the neck: a retrospective study. Injury 1988;19:393-6.

15 McNamara RM, O'Brien MC, Davidheiser S. Posttraumatic neck pain: a prospective and follow-up study. traumatic neck pain: a prospective

16 Norris SH, Watt I. The prognosis of neck injuries resulting from rear-end vehicle collisions. F Bone foint Surg B 1983;65:608-11.

17 Pennie B, Agambar L. Patterns of injury and recovery in whiplash. Injury 1991;22:57-59.

18 Bovim G, Berg R, Dale LG. Cervicogenic headache: anaesthetic blockade of cervical nerves (C2-C5) and facet joint (C2/C3). Pain 1992;49:315-20.

19 Wickstrom J, Martinez JL, Rodriguez R, Jr., Haines DM. Hyperextension and hyperflexion injuries to the head and neck of primates. In: Gurdjian ES, et al, eds Neckache

20 Abel MS. Occult traumatic lesions of the cervical vertebrae. CRC Critical Reviews in Clinical Radiology and brae. CRC Critical Reviews in Clin
Nuclear Medicine 1975;6:469-553.

21 Clemens HJ, Burow K. Experimental investigation on injury mechanisms of cervical spine at frontal and rearfrontal vehicle impacts. In: Proceedings of the Sixteenth STAPP Car Crash Conference. Warrendale: Society of Automotive Engineers, 1972:76-104.

22 Jónsson H, Jr., Bring G, Rauschning W, Sahlstedt B Hidden cervical spine injuries in traffic accident victim with skull fractures. $\mathcal{F}$ Spinal Disord 1991;4:251-63.

23 Clark CR, Igram CM, el Khoury GY, Ehara S Radiographic evaluation of cervical spine injuries. Spine 1988;13:742-7.

24 Woodring JH, Goldstein SJ. Fractures of the articular processes of the cervical spine. Am F Roentgenol 1982; 139:341-4."

25 Barnsley L, Lord SM, Wallis BJ, Bogduk N. Lack of effect of intra-articular corticosteroids for chronic pain in the cervical zygapophysial joints. $N$ Engl $f$ Med 1994;330: cervical zygar $1047-50$.

26 McCormick C. Arthrography of the atlanto-axial (C1-C2) joints: techniques and results. Fournal of Interventional joints: techniques and

27 Ehni GE, Benner B. Occipital neuralgia and the C1-2 arthrosis syndrome. F Neurosurg 1984;61:961-5. 